\title{
Taste-making in turbulent times: Vogue and its social networks
}

\author{
Rachel Matthews, Australian College of the Arts \\ rmatthews@collarts.edu.au
}

\begin{abstract}
Vogue is a long-standing taste-making institution, with a reputation for drawing together a selection of the most fashionable people, places, and products in its monthly magazine. In the mass-communication systems of the twentieth century, expert knowledge conveyed through monthly magazines was important and effective. However, the digital context of the twenty-first century enables instant access to fashion information, influences and influencers, allowing us to be as informed as many experts. The paper uses Actor-Networks (Latour, 2005) to examine the evolution of taste-making practices in fashion communication. Content from British Vogue May 1967 and May 2017 provides the data for a comparative analysis of changing methods of influence in fashion. This qualitative case study considers how Vogue has responded to the networked conditions of the contemporary communication environment and what its digital strategy can reveal about new methods of influence. It identifies how the ongoing structural changes to fashion communications continue to reshape institutional tastemakers such as Vogue, online and offline.
\end{abstract}

Keywords

Vogue, taste, influence, networks, taste-making

\section{Introduction}

Fashion magazines have been an important method of circulating information on fashion style and taste, with Vogue a dominant title in this field for over a century. In the mass-communication systems of the twentieth century, the magazine format was an important and exclusive resource for those interested in fashion. However, the digital context of the twenty-first century has revolutionised our access to fashion information and changed the way we engage with fashion media. Fashion ideas distributed via magazine format now exist alongside a variety of fast moving, interactive competitors.

Despite the demise of some magazines and a decrease in circulation figures, Vogue stands as a highly-regarded and influential brand in the fashion media landscape, with the magazine central to its profile. However, to maintain relevance and to compete in these networked and fast-moving conditions, it has had to evolve. This paper uses the magazine as the starting point to explore the changing methods of influence in fashion communication by comparing
British Vogue magazine from May 1967 with Vogue from May 2017.

The fashion magazine has been the subject of analysis in areas of fashion studies, social sciences and cultural studies, used to explore media and communication practices (Moeran, 2004; Rocamora, 2009), commerce and consumer influence (McCracken, 1993; Crane, 2000) as well as gender and identity construction (Jobling, 1999; McRobbie, 1996). The Fashion System by Roland Barthes (1967) details a significant semiotic analysis of how fashion magazines produce 'fashion' through word and image. Through this work, Barthes established a foundation for research into fashion magazines as cultural products, and offers insight into the fashion system through the signs and linguistic systems that communicate 'fashion.' The studies undertaken in the twentieth century have analysed the fashion magazine situated in systems of mass communication, before the media communication landscape was transformed by digital networked technologies. Fashion magazines have subsequently been examined at the intersection of so-called old and new media as much 
of society integrates mobile communication into their daily practices (Rocamora, 2012; Moeran, 2015; Lynge-Jorlen, 2012). Inevitably, much of the investigation into contemporary fashion media has shifted to blogs (Rocamora, 2011; Pham, 2011; Titton, 2015 amongst others), fashion film and video (Khan, 2012), as new modes fashion communication emerge.

This paper adopts a socio-cultural perspective on the magazine as a social object and examines both its position in relational networks, and its significance as a node in online and offline networks. It begins by detailing the theoretical positons and methods that have informed the research, before describing a range of findings from content analysis undertaken of British Vogue May 1967 and May 2017. The comparative case study highlights the changing characteristics of content, communication channels and message making. The analysis provides new insight on how fashion taste-making institutions (such as Vogue) that were established during an era of mass-communication are adapting to contemporary networked conditions. Further, the findings, whilst drawn from limited data, suggest an underlying adjustment to the way concepts of fashionable taste are made meaningful in the twenty-first century.

\section{Method}

The magazine has been described as 'a bounded entity' (Fuery, 2009), and indeed its covers create the impression of a singular unit. However, this paper explores how the magazine can be understood as the material effect of an interacting network of heterogeneous entities; representing a network consolidation. Underpinning this approach is Actor-Network Theory (ANT) proposed as an alternative social theory by Bruno Latour (2005).

Latour's theory considers the associations and relations of human and non-human 'actants' and proposes a new understanding of the 'social' through a focus on the interconnections that make up collectives, networks or assemblages
(Latour, 2005). He uses the term 'actant,' rather than 'actor' to capture any manner of things that play an active role in shaping associations. This is particularly relevant to fashion, where many interactions and communication practices are mediated through objects, situations, bodies and equipment. In this case study, the magazine represents a convergence or consolidation of such a network (Law, 1992). Further, emphasis on the network in Latour's theory provides a relevant structure for the analysis of communication. The characteristics of a network are used to identify the nodes and links that shape Vogue's social networks (beyond its magazine covers), whether through technological processes or as social practices.

In combination with Latour's notion of actor-networks, this research uses discourse analysis to examine the taste-making content within Vogue. It adopts Michel Foucault's ideas on discourse and discursivity that propose a broad set of 'statements' converge to form popular discourses that influence what is 'sayable' and 'thinkable' about a topic at a particular historical moment (Hall, 1997, p. 73). Foucault proposes that certain discourse emerges across a range of texts, in actions and conduct, and at a range of institutional sites, thus characterising a way of thinking or state of knowledge. This perspective expands the scope of what is involved in knowledge production and representation and is fitting for the diverse nature of 'fashion statements' made in contemporary fashion communications.

The work of both Latour and Foucault have guided the research strategy here, in order to understand events and effects that occur through interaction, convergence and connection, rather than through separation, boundaries and division. They also bring issues of materiality and practice into the analysis of social behaviour, two important characteristics of fashion communication.

The paper uses detailed content analysis of two British Vogue magazines (May 1967 and May 2017), produced fifty years apart, as a way of breaking apart and identifying the taste-making entities assem- 
Figure 1: Network mapping and visualisation: British Vogue May 1967 and May 2017

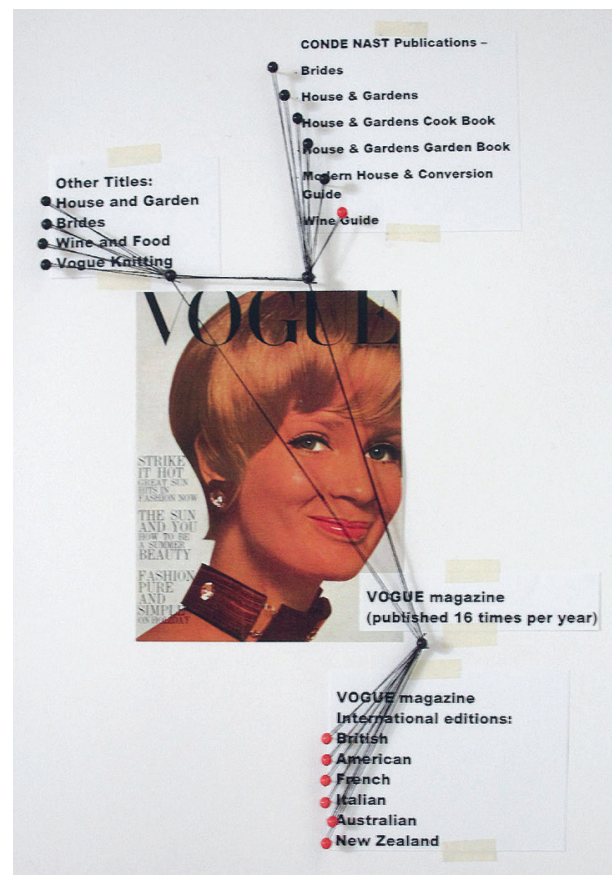

Note. Illustration by Matthews (2017).

bled in each edition. This comprehensive examination classifies all 'actants' as either explicit elements if they are included in editorial features, or implicit elements if included in advertising. Products, people, places and activities make up both the editorial and advertising content. Scrutiny of this content also reveals the shape of Vogue's communication networks, a mesh of interconnections that reaches well beyond the magazine cover. Visual mapping techniques have been used both as a process of data gathering and as a method of data analysis (Cosgrove, 1999). This is an approach adapted from critical cartography and is used as a way to visually document and interpret actor-networks and discursive formations.

\section{Results: Content analysis}

The comparative qualitative analysis of the two editions of Vogue magazine offer some clear physical differences in the

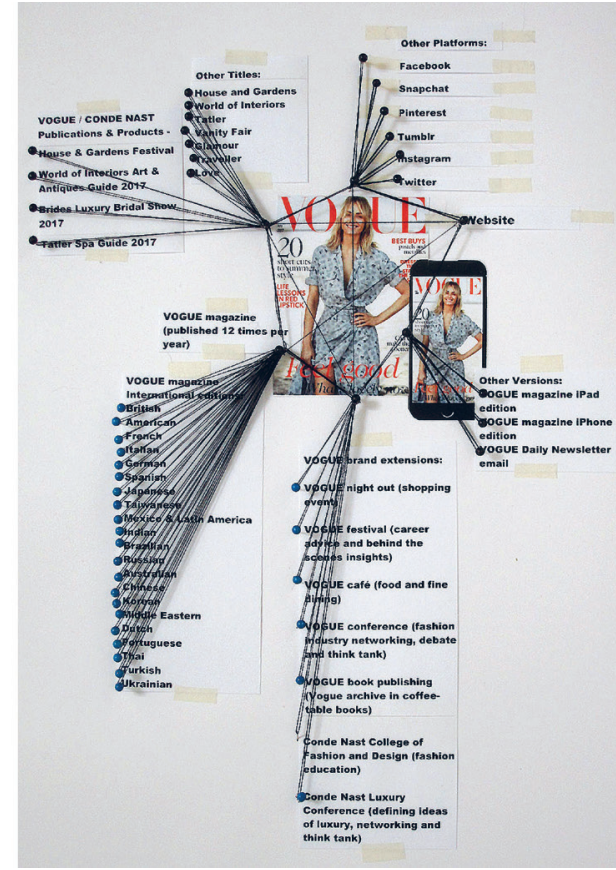

production of the magazine. May 1967 has a larger page format, but less pages than the May 2017 edition (1967 $=170$ pages / $2017=248$ ). The thickness and glossiness of the pages in May 2017 stands in contrast to the matt and rather 'papery' quality of May 1967. There is also a noticeable difference in the quality and quantity of colour reproduction between the two editions, with May 2017 containing vibrant colour saturated images throughout, while May 1967 has colour on covers (front and back), but very limited use of colour in editorial images (with a majority of fashion images in black and white). It is the advertising in May 1967 that brings colour to the magazine content.

There are differences in distribution channels, Vogue edition in 2017 is available across a range of formats including mobile phone and iPad. This alters the material quality of the magazine experience, whilst extending accessibility. In 2017 Vogue magazine is published monthly and has 21 International editions, whereas in 1967 
Vogue magazine was published 16 times per year with six International versions. Figure 1 (Network Mapping and Visualisation: British Vogue May 1967 and British Vogue May 2017) illustrates the changing communication channels of Vogue between 1967 and 2017.

The content of each magazine details further communication channels of Vogue content. In 2017, Vogue content is created and edited for the Vogue (UK) website, Facebook, Snapchat, Pinterest, Tumblr, Instagram and Twitter. The magazine also promotes multiple offline, face-to-face immersive Vogue experiences to be had in 2017, such as Vogue night out (shopping event), Vogue festival (career advice and behind the scenes insights) Vogue café (food and fine dining) and Vogue conference (fashion industry networking, debate and think tank event). In addition to the Vogue brand extensions, the magazine publicises Condé Nast (Vogue's parent company) enterprises. These include promotion of other magazine titles - House and Gardens, World of Interiors, Tatler, Vanity Fair, Glamour, Traveller and Love as well as Condé Nast College of Fashion and Design (fashion education), and Condé Nast Luxury Conference (discussing the changing notion of luxury). This cross-promotion of other Vogue and Condé Nast publications was also evident in 1967, although to a lesser extent. Titles such as House and Garden, Brides, Wine and Food and Vogue Knitting are publicised in May edition of 1967. The details of these extended communication are included in Figure 1 to build a picture of Vogue's network connections

In considering the seismic changes that media communications have undergone in recent times, a comparison of these magazines reveals two very different communication networks. Unsurprisingly, the analysis details a much more complex system of links and nodes that reflects a greater (physical and virtual) reach in May 2017 compared to May 1967.

\section{Explicit content analysis}

The comparative analysis of magazine content in this research sub-divides the material into explicit content and implicit content. In Figure 2 (Visualisation of Content Analysis: British Vogue 1967) and Figure 3 (Visualisation of Content Analysis: British Vogue 2017), explicit content is detailed in the inner circle of the diagrams while implicit content is mapped in the outer circle. This distinction reflects the difference between items that Vogue staff felt were important to include, and those items that have paid to be included. Although this distinction provided useful structure for the analysis process, there are some elements, such as advertorials or Vogue promotions that are difficult to classify in this way.

Comparison of the explicit content in 1967 and 2017 reveals marked similarities and differences. Although both editions of Vogue contain content that details a selection of fashionable products, people, places and activities, the way these elements are framed in the magazine content displays stark differences. The number of product types discussed in the editorial content in May 1967 appears very limited compared to May $2017 \quad(1967=15$, 2017 = 27; see Figure 2 and 3). In the earlier edition, there are very few images of the products, other than garments, included for discussion and where images are included, these are in black and white. Fashion products (garments and accessories) are discussed using a range of simple descriptors such as beachwear, city-daywear, eveningwear or young ideas. In comparison, all products whatever their type are accompanied with styled colour visuals in the editorial content in 2017. Fashion products are grouped and themed in numerous and creative classifications. So, types of dressing become sub-divided offering multiple options around times of day, attitude, location and colour palettes, in fashion features such as "20 Ways to Summer-ise your Style" and "How to make Pink Chic."

Of specific interest regarding the explicit content, is the way books, jewellery, 
beauty products and the home are treated very differently in Vogue magazine fifty years apart. Books feature in both editions; however, in 1967 their inclusion is as a list of book reviews that evaluates the quality of the writer or story. In 2017, the books included are briefly described in terms of their visual appearance and suitability as a coffee table book. Jewellery is framed as an investment by a contributing writer from the Financial Times in 1967, whereas today jewellery (including items with precious stones) is presented as an essential fashion accessory. The beauty content in 1967 lists products that specifically target the outside appearance of the body; descriptions of tanning, hair dyeing or hair perming products are framed as aids to achieving a particular notion of female appearance. Beauty features more heavily in 2017, and the list of products extends to treatments, services and experiences with a focus on holistic wellness rather than perfecting a particular exterior appearance. Nutrition, exercise and meditation emphasise 'natural' approaches to beauty and wellness in this product category in 2017. The home and its products feature in both editions of Vogue. In 1967, it forms the backdrop for discussions of hospitality and home-making, for example, in an article that describes how to make alcoholic drinks that will compliment salads (including what type of glasses in which to present the drinks). In 2017, the home is referenced as a place to display tastes and inspirations or as a reflection of identity and lifestyle. This is exemplified in an article that takes the reader inside the home of American designer Tory Burch (The Tory Vote).

However, there is a more significant and over-arching observation from the detailed content analysis of these two magazines, concerned with the people who contribute and converge in these magazines (as network consolidations). In Vogue from May 1967, there is little evidence of the people who produce the content of the magazine. There is a discreet list of staff on the contents page, photographers are credited in photo shoots and there are two short profiles of contributing writers. However, there are no credits for the models (even where Jean Shrimpton and Twiggy feature), and no credit for hair, make-up or styling. Notably, many articles do not acknowledge a named author. In 1967, there are only two articles that profile individuals, these are actors and an artist. There is also a short piece on selected social engagements attended by minor aristocracy and foreign royalty, with noone from the world of fashion mentioned.

In Vogue 2017, almost everyone who has contributed to content has both a credit and a short profile. There is a section included after the contents pages dedicated to contributing photographers and writers (with mini biographies). Vogue staff are highly visible, with three articles written from a first-person perspective by magazine staff. Throughout the explicit content in 2017, there are a broad range of people profiled from across fashion and beyond. Artists, musicians as well as actors from across film and television are included, with extensive information about their childhood, home life and professional pedigree. In addition, people from across fashion, beauty and lifestyle, ranging from emerging names through to established figures form a central part of the contemporary content of Vogue.

Of course, both magazines draw together different types of entities that form notions of fashion because of the perpetual changing nature of fashion. However, there is also a shift in the discourse on "fashionableness" between the two magazines. In May 1967, despite the emergence of new young fashion during this period, the discourse defines certain boundaries of fashion, focusing on appropriate physical appearance and behaviours. In May 2017, pluralistic concepts of fashion emerge, opening up the nature of fashionableness beyond the consumption of products and dressing up. Rather than defining, it suggests multiple ways one can participate in fashion, for example, via experiences and interactions with others and by employing methods of self-improvement that work from the inside as well as the outer appearance of the fashionable self. 
Figure 2: Visualisation of content analysis: British Vogue 1967

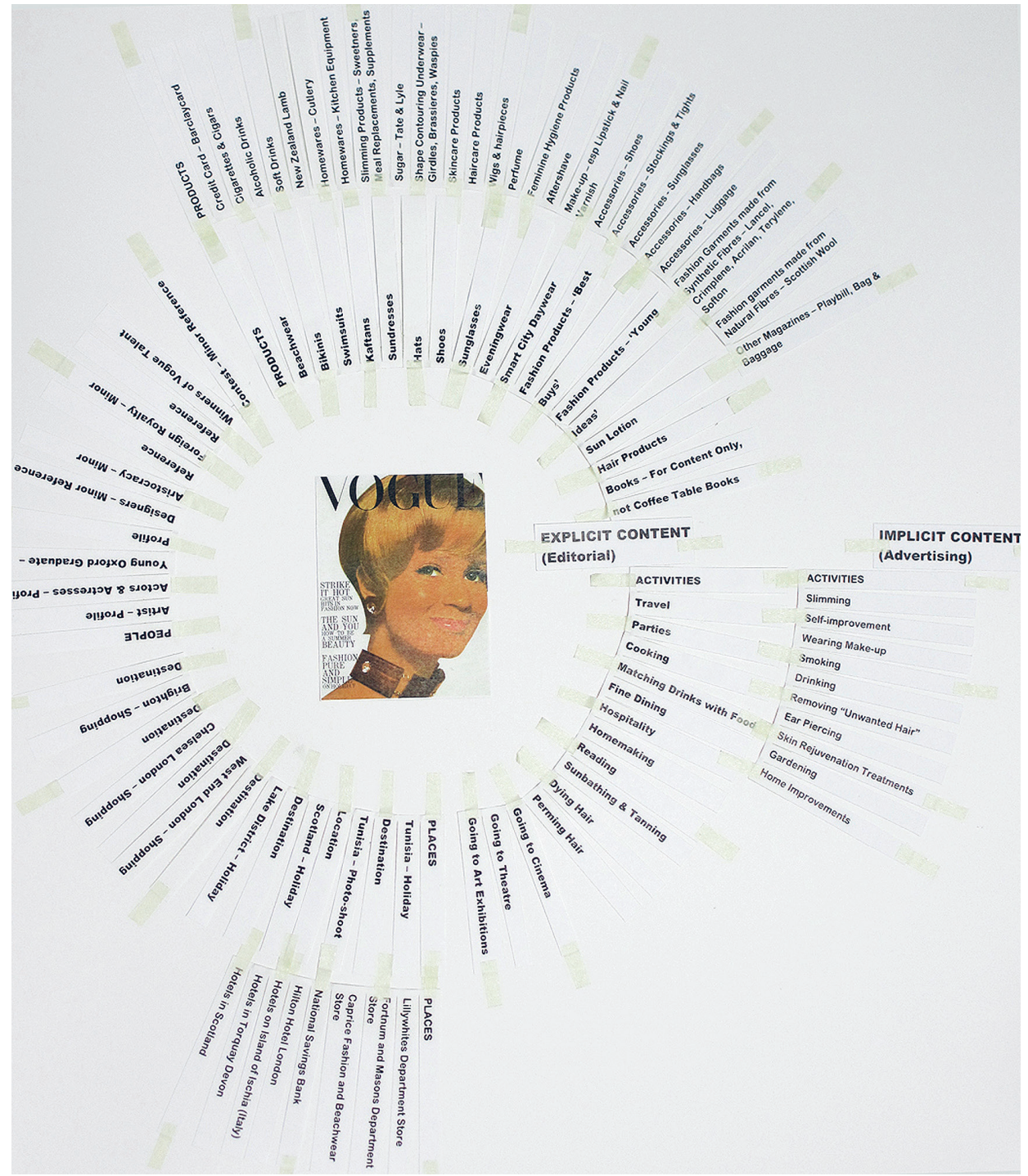

Note. Illustration by Matthews (2017).

\section{Implicit content analysis}

Analysing the implicit content in the form of advertising provides further insights on the shifting relational networks of Vogue. Although this material is included for a fee, the nature of this content reflects research (and assumptions) about Vogue readers.

In comparing the advertising content from 1967 and 2017, there are certain dif- ferences in format. In May 1967, there are full page colour adverts throughout the magazine, but there are also a large number of small (quarter page or less) text based adverts, with little or no image. In May 2017, there are some strip or half page adverts and all advertising content is in colour with images. Both magazines have an extensive classified section at the back of the magazine, even this has some ac- 
Figure 3: Visualisation of content analysis: british vogue 1967

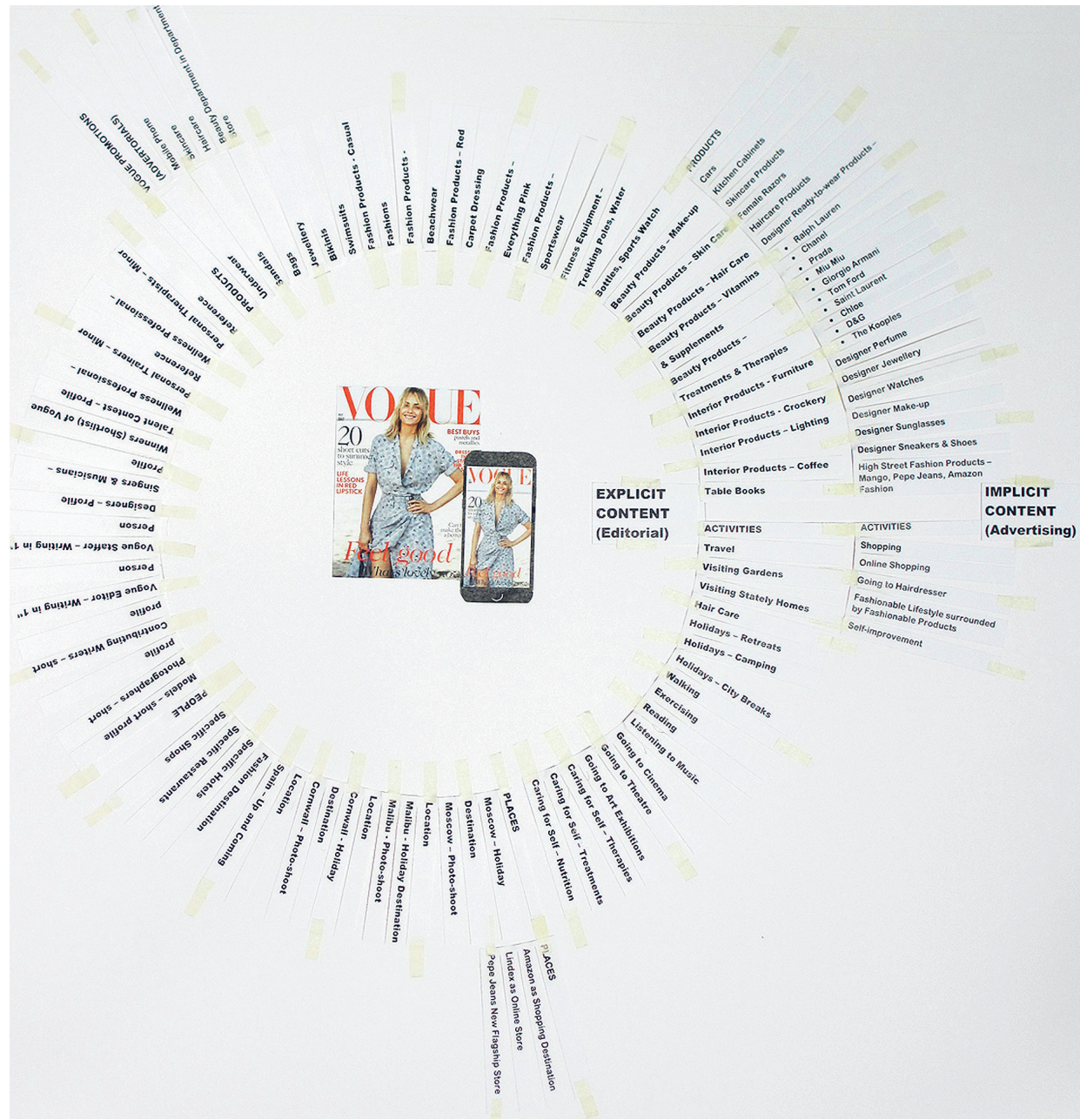

Note. Illustration by Matthews (2017).

companying photographs in 2017 compared to 1967.

Both magazines have full colour multi-page adverts in their implicit content. In the earlier edition, multi-page advertisements are dedicated exclusively to synthetic fibres such as Crimplene and Terylene. These adverts resemble fashion shoots with models wearing 1960s style dresses made of the synthetic fabrics. The contemporary edition has multi-page adverts that also resemble editorial fashion shoots; however, these pages show only luxury designer brands that use the space to promote new collections of garments, accessories, perfume and lifestyle.

The findings of the comparative analysis of the implicit content gives a contrasting picture of product types promoted in the two magazines $(1967=28,2017=15$; see Figure 2 and 3). In 1967, items range from wigs and slimming products through to New Zealand lamb, cigarettes and aftershave. This stands in contrast to the limited product range included in the 2017 edition, which is restricted almost exclusively to fashion garments and fashion accessories with the exception of two adverts for 
beauty products. Advertisements found in both editions do employ global locations, such as Paris or Italy, as a signifier of quality and sophistication. They do this in the imagery used as well as including written reference, whether for wine, perfume or as a place of origin for handcrafted accessories and watches.

There are different themes that emerges through the implicit content of these two magazines produced fifty years apart. A large portion of adverts in 1967 promote products for the physical improvement of the female self; wigs and hair-pieces, contouring underwear and slimming products, make-up and 'unwanted hair' removal products that will all help to tame the imperfect female body. There is emphasis on improving exterior appearances in order to please others. However, in 2017 the implicit content focuses on fashion products and accessories and the lifestyle implications of their branding. There is almost no reference to physical self-improvement, rather the emphasis is on fulfilment of the self through brand/product investment.

\section{Discussion}

Content from British Vogue May 1967 and May 2017 provides the data for a comparative analysis of changing methods of influence in fashion. How has Vogue evolved in response to the networked conditions of the contemporary fashion communication environment? What can Vogue magazine content and its digital strategy tell us about new methods of influence and taste formation in twenty-first century?

This case study provides insight on how Vogue has extended its reach in today's networked fashion communication environment. Vogue produces multiplatform content and engages its users through all media channels, whilst maintaining the tangible experience of the magazine as part of its communication strategy. Vogue has also developed other avenues of brand communication; multiple face-to-face immersive activities that demonstrate the accumulation of creative and cultural knowledge and resources of the brand - education, industry presentations, think-tank conferences, festivals about careers in fashion as well as shopping and retail events. These offline activities offer a way for 'Vogue the institution' to connect and engender trust through interpersonal means and mark an adjustment in the relational networks within which Vogue is situated, in contrast to the bounded or closed experience of Vogue magazine in 1967.

Analysis of explicit content notes an expansion in the range of people, products and activities in Vogue of 2017, whilst variety of products advertised had contracted. The discourse around the wide assortment of people, products and activities connects fashion with the broad cultural landscape and proposes fashion as something that is accessible for everyone. It addresses its readers as more informed, experienced and discerning than their 1967 counterpart. In 2017, Vogue readers do not employ fashion for social competition or conformity; rather they presume contemporary consumers draw on a range of fashion objects, knowledge and experiences for pleasure, empowerment and entertainment, so they propose multiple options. Furthermore, the shift in explicit content towards symbolic consumption of services (through engagement with nutritionists or therapists) as non-material displays of taste, further diversifies notions of fashion luxury and exclusivity in Vogue.

Vogue in 2017 draws on a variety of voices to convey its views on fashionable taste. It no longer seeks to send a singular or specific message about what is 'in' fashion or the height of taste each month. The content is distinctly people focused, individuals are made visible, human and relatable through first-person articles, candid self-portraits and personal information. This gives the fashion messages in Vogue variation and a level of authenticity. By highlighting the collection of different people whose views are captured in Vogue, the fashionable message gets expressed and diffracted. It also has the effect of breaking down "Vogue the institution" into 
something resembling a collective of individual contributors.

So, what does this tell us about methods of influence and taste formation in the twenty-first century? Recent studies of fashion communication have focused on the power of social media influencers (bloggers, Instagram stars and Youtube vloggers) to command attention and promote fashionable taste. This reflects a social shift, where the fashion consuming public seek out stylish individuals who are able to competently demonstrate a version of fashionable taste on a level that is more accessible to them, in preference to fashion institutions. The examination of Vogue magazine and its social networks in 2017, demonstrates how this established institutional tastemaker is adjusting its messages and practices to break down its perception as an institution, by putting people, their lives (including their vulnerabilities and experiences) out for public consumption. Further, by ensuring that all contributors are named and given a profile including a picture and personal details, the monthly magazine becomes more akin to a creative assemblage or forum - rather than a monthly edict from a large organisation.

The shift in consumer preference from institutional tastemakers to the tastes communicated through individual performance suggests a need to consider alternative or changing conception of taste formation. Many studies of taste formation and the impact of media and communications on taste are founded on Pierre Bourdieu's work, Distinction: A Social Critique on the Judgement of Taste (1984). Bourdieu's formulations are based on French society during the 1960s and 1970s. For him, taste is a device to create visible difference from other sections of society and to shore up one's own social position, it is about separation and division (Bourdieu, 1984 , p. 59-60). The consumption of culturally significant products and the associated performance of consumption are central to his ideas on how taste works as a means of "fitting in" or "standing out" in society. Products (including fashion objects), are given meaning by institutional mediators (such as magazine editors), in order to function as a sign, with the subjects reproducing existing social hierarchies.

The actor-networks and discursive formations analysed in the May 2017 edition of Vogue do not promote a clear designation of fashionable taste that, if followed, create visible difference from other sections of society. Vogue seeks to present multiple modes of fashionable taste and more plural views on fashionable objects, ideas, settings and activities. To reflect this and the change in public preference away from institutional influences, this paper proposes that Antoine Hennion's ideas on taste formation provides a useful lens on contemporary mechanisms of influence on fashion. In the Pragmatics of Taste (Hennion, 2004), Hennion outlines a theory that understands taste and taste-making as reflexive practices performed in and through our attachments to objects and communities, in relations with others and relations with ourselves (Hennion, 2004, p. 131). His ideas have been developed in the social conditions of the twenty-first century and seek to open up taste to a greater diversity of analysis. Hennion shares Latour's focus on the interconnection between subject and object and between the human and non-human proposed in ANT (Hennion \& Muecke, 2016, p. 291).

Activities that develop our tastes, are described as acts of tasting or experimental interactions that help to bring forth differences "in" objects and "in" the sensibilities of the taster (Hennion et al, 2005, p. 675). So, our taste emerges through acts of tasting, but is further shaped and advanced by the gestures and behaviours that accompany it, by the support and response it receives from others and on-going adjustments and re-alignments as our associations develop. Many sources and elements inform and influence our subjective experience. His view of how taste develops more closely aligns with multi-layered methods of influence that accumulate through our online and offline interactions. This conception of taste formation enables a consideration of the micro/macro nature of contemporary fashion 'statements.' 
Hennion's ideas on taste formation provide a useful perspective in this study. He describes taste as "based on mediations, bodies, objects, situations and equipment" (Hennion, 2004, p. 136) that converge and help to create attachments. This has the potential to capture the way we engage with fashion across media platforms, interacting with different elements in the noisy crowded communication landscape as well as our lived experiences of fashion. In addition, it enables a new perspective on the adjustments that Vogue is making to its taste-making practices, breaking down its institutional perception. This perspective enables a clearer understanding of how an interacting network of heterogeneous entities can take effect on our taste in the contemporary fashion communication context.

\section{Conclusion}

The purpose of this paper has been to explore the evolution of taste-making practices through an examination of Vogue magazine as a long-standing and well-regarded fixture in fashion media. It uses two editions of British Vogue produced fifty years apart (May 1967 and May 2017) as a starting point, recognising the magazines as the material effect of a network consolidation. Employing the concept of actor-networks as well as content and discourse analysis, this paper has identified certain changes in Vogue over fifty years, both as a social object and its role in producing networks of meaning in fashion.

There are a number of physical and visual differences between the two magazines including the quantity and quality of colour image content. As detailed above, there are also changes to the types of products, brands and activities included in the advertising content, notably the growth of Vogue and Condé Nast brand extensions. However, the key findings emerge from the comparative analysis of the explicit content. Vogue magazine content has evolved over time to promote a breadth of ways to be fashionable. It constructs conceptions of fashion that are not simply concerned with dressing up, but that exist in situations and locations, through services and experiences, also via health and well-being.

In May 2017, the content is distinctly "people" focused. The adjustments in Vogue's practices resonate with the working methods of today's social influencers, who have reshaped and personalised the fashion communication and taste-making practices over the last decade. These individuals engender trust and effect influence on fashionable taste through interpersonal communications about their lived experiences.

This paper argues that the shifting communication practices captured in the magazine are a means of changing the perception of Vogue as a hierarchical institution that seeks to dominate fashionable taste. Their promotion of a wide variety of fashionable entities depict fashion as a plural domain, down-playing former notions of exclusivity. The multiple brand extensions that facilitate different types of face-to-face or immersive fashion experiences removes the perceived boundaries around fashion defined by insiders and outsiders. These changes create the impression of Vogue as a creative collective, with eclectic individuals contributing their own ideas and perspectives on how to be fashionable.

The idea of "Vogue, the institution" appears to influence the brand's activities along two very different paths. On one level, Vogue plays on its heritage and long-standing reputation to invoke stability and trustworthiness; demonstrated by its venture into fashion education and fashion conferences, for example. On another level, Vogue seeks to diminish the idea that it is a well-established and stable institution. Through emphasis on the variety of its creative contributors and operations across social media platforms it encourages readers to see it as agile and adaptable in 2017; to see it as a brand capable of communications that are as fluid and individual as any of today's social influencers.

In the turbulent and digitally disrupted era of fashion communication, it is easy 
to overlook the fashion magazine, classifying it as out of date. Nevertheless, if the magazine can be understood as an opportunity to study the convergence of network effects in contemporary communication practices - it still has much to offer.

\section{Limitations}

The examination of Vogue magazine from 1967 and 2017 has undoubtedly provided insights into the changes to fashion communications and the operations of Vogue as a taste-making entity over this period. However, the highly selective nature of material examined here makes it unwise to draw broad conclusions regarding other institutional tastemakers or to make wide-ranging assumptions about contemporary fashion communication practices. The data drawn upon here is extremely limited and over a fifty-year span. Further understanding would be gained from exploring the extensive archive of material in Vogue's back catalogue and would benefit from quantitative as well as qualitative examination.

\section{Future research}

The findings of this paper suggest the need for further research into institutional fashion tastemakers and their evolving communication practices. The fashion media environment, with its ability to engage and interact with consumers to produce material and immaterial effects has much to offer investigations in this area. For future research, adopting Antoine Hennion's perspective to understanding taste formation would provide an opportunity to fully explore the increasingly networked nature of taste-making practices that are enacted online and offline. This topic would benefit from a longitudinal study that maps the extended networks of fashion tastemakers and the multiple actants that converge in contemporary fashion statements; this would offer more detailed insights on where and how the tastemakers' perspec- tives intersect with personal tastes and our lived experience of fashion.

\section{References}

Barthes, R. (1967). The fashion system, translated by M. Ward \& R. Howard. New York: Hill and Wang.

Borelli, L. (1997). Dressing up and talking about it: Fashion writing in Vogue from 1968-1993. Fashion Theory, 1(3), 247-260. doi:10.2752/136270497779640143

Bourdieu, P. (1984). Distinction: A social critique of the judgement of taste, translated by R. Nice. London: Routledge.

Cosgrove, D. (1999). Introduction: Mapping meaning. In D. Cosgrove (Ed.), Mappings (pp. 1-23). London: Reaktion.

Crane, D. (2000). Fashion and its social agendas: Class, gender and identity in clothing. Chicago: The University of Chicago Press.

Entwistle, J. (2016). Bruno Latour: Actor-Network theory and fashion. In A. Rocamora and A. Smelik (Eds.), Thinking through fashion: A guide to key theorists (pp. 269284). London: I.B. Tauris.

Foucault, M. (2002). The archaeology of knowledge. Oxford: Routledge.

Foucault, M. (2002). The order of things: An archaeology of the human sciences. London: Routledge.

Hall, S. (1997). Foucault: Power, knowledge and discourse in the work of representation. In S. Hall (Ed.), Cultural Representations and Signifying Practices (pp. 13-74). London: Sage.

Hennion, A., Teil, G., \& Vergnaud, F. (2005). Questions of taste. In B. Latour and P. Weibel (Eds.), Making things public: Atmospheres of democracy (pp. 670-677). Cambridge, MA: MIT Press.

Hennion, A. (2004). Pragmatics of taste. In M. Jacobs and N. Hanrahan (Eds.), The Blackwell companion to the sociology of culture (pp. 131-144). Oxford: Blackwell.

Hennion, A. (2007). Those things that hold us together: Taste and sociology. Cultural Sociology, 1(1), 97-114. doi:10.1177/1749975507073923

Hennion, A., \& Muecke, S. (2016). From ANT to Pragmatism: A journey with Bruno 
Latour. New Literary Theory, 47(2) 289-308. Titton, M. (2015). Fashionable Personae: doi:10.1353/nlh.2016.0015

Khan, N. (2012). Cutting the fashion body: Why the fashion image is no longer still. Fashion Theory, 16(2), 235-249. doi:10.2752/17 $5174112 X 13274987924177$

Jobling, P. (1999). Fashion Spreads: Words and Images in fashion Photography since 1980. Oxford: Berg.

König, A. (2006). Glossy words: An analysis of fashion writing in British Vogue. Fashion Theory, 10(1/2), 205-224. doi:10.2752/136270406778051085

Latour, B. (1996). On interobjectivity. Mind, Culture and Activity, 3(4), 228-245. doi:10.1207/s15327884mca0304_2

Latour, B. (2005). Reassembling the social: An introduction to Actor-Network theory. Oxford: Oxford University Press.

Law, J. (1992). Notes on the theory of the ActorNetwork: Ordering, strategy and heterogeneity. Systems Practice, 5(4), 379-393. doi:10.1007/BF01059830

Lynge-Jorlen, A. (2012). Between frivolity and art: Contemporary niche fashion magazines. Fashion Theory, 16(1), 7-28. doi:10.2752/175174112X13188318404104

McCracken, E. (1993). Decoding women's magazines: From Mademoiselle to Ms. London: Macmillan.

Moeran, B. (2006). More than just a fashion magazine. Current Sociology, 54(5), 725-744. doi:10.1177/0011392106066813

Moeran, B. (2004). A Japanese discourse of fashion and taste. Fashion Theory, 8(1), $35-62$.

Moeran, B. (2013). Proposing Fashion: The discourse of glossy magazines. Communicacao e Sociedade, 24(1), 120-142.

Pham, M. (2013). Susie Bubble is a sign of the times: The embodiment of success in the web 2.0 economy. Feminist Media Studies, 13(2), 245-267.

Rocamora, A. (2006). Over to you: Writing readers in French Vogue. Fashion Theory, 10(1/2) 153-174.

Rocamora, A. (2011). Personal Fashion Blogs: Screens and mirrors in digital self-portraits. Fashion Theory, 15(1), 407-424.

Rocamora, A. (2012). Hypertextuality and remediation in fashion media. Journalism Practice, 6(1), 92-106. 